\title{
CRÓNICA LATINOAMERICANA: LAS REVISTAS, HÁBITAT NATURAL DEL PERIODISMO BIEN HECHO
}

\author{
Andrés Alexander Puerta Molina \\ Universidad de Medellín, Medellín, Colombia \\ andrespuerta@udem.edu.co
}

\begin{abstract}
RESUMEN / ABSTRACT
Este artículo es resultado de la investigación Crónica latinoamericana actual: lo maravilloso real. Análisis del periodismo narrativo de Alberto Salcedo Ramos, presentada por el autor para obtener el título de Doctor en Lenguajes y Manifestaciones Artísticas y Literarias en la Universidad Autónoma de Madrid y busca mostrar la importancia que han tenido las revistas en la vitalidad de la crónica latinoamericana actual. El hecho de desarrollarse, en buena medida, por las revistas, emparenta este fenómeno con el Nuevo Periodismo en Estados Unidos; este tipo de publicaciones ha permitido un auge del periodismo narrativo en América Latina.
\end{abstract}

Palabras clave: crónica, Latinoamérica, revistas, Nuevo Periodismo.

\section{LATIN AMERICAN CHRONICLE: MAGAZINES, NATURAL HABITAT OF QUALITY JOURNALISM}

This article is a result of the research project Crónica latinoamericana actual: lo maravilloso real. Análisis del periodismo narrativo de Alberto Salcedo Ramos presented by the author for the degree of Doctor in Lenguajes y Manifestaciones Artisticas y Literarias at Universidad Autónoma de Madrid and tries to show the role played by magazines in the vitality of the current Latin American chronicle. The fact that this has been developed by magazines links it to New Journalism in the United States, and such publications have allowed a boom in narrative journalism in Latin America.

KEYWORDS: chronicle, Latin America, magazines, New Journalism.

Recepción: 30/10/2017

Aprobación: 22/01/2018 


\section{INTRODUCCIÓN}

En las décadas del sesenta y el setenta se presentó en Estados Unidos una conjunción de hechos, movimientos, situaciones, personajes, inventos, rebeldías pocas veces vistas en una sociedad. La contracultura, la rebelión de los estudiantes contra el American Way of Life, la rebelión de los negros contra la segregación racial, la revolución sexual, la psicodelia y la cultura de la droga, los movimientos de liberación de la mujer, las protestas contra la guerra de Vietnam, el movimiento hippie. Relatar tales cambios requería una manera diferente para contar; en esta época surgió el denominado Nuevo Periodismo norteamericano, que tuvo como espacio privilegiado una serie de revistas como: Esquire, New York, Ramparts, The New Yorker, The Village Voice, Playboy, Harper's Magazine, Rolling Stone, The New York Herald Tribune, The New York Times Magazine, que fueron el hogar y también sirvieron como mecenas para un grupo de escritores que sacudieron los cimientos del periodismo como se conocía. No inventaron nada, sus recursos ya habían sido usados; pero los popularizaron, los convirtieron en un producto apetecido por la gente. Las revistas tuvieron éxito comercial y los autores escribieron best sellers.

Personajes como Tom Wolfe, Jimmy Breslin, Gay Talese, Hunter S. Thompson, Joan Didion, John Sack o Michael Herr se convirtieron en innovadores definitivos de la prosa y enriquecieron el trabajo que ya habían realizado otros escritores y periodistas como Truman Capote o Norman Mailer. En esta labor también fueron muy importantes editores como Harold Hayes, Clay Felker o Jann Wenner, quienes tuvieron el olfato, la intuición y la capacidad para asignar y enriquecer historias.

Últimamente se habla de un boom de la crónica en América Latina. Guardadas las necesarias proporciones, es en las revistas donde la crónica latinoamericana ha encontrado un espacio, dado que muchos temas han surgido a su amparo y otros han sido financiados por ellas. Muchos autores han pulido o han encontrado un estilo en estas publicaciones. La crónica latinoamericana actual ha encontrado un espacio natural y propicio en las revistas. 


\section{METODOLOGÍA}

El proceso de la investigación comprendió la lectura interpretativa desde una perspectiva semiótica de libros y de revistas que contenían una serie de crónicas. Los textos que indagan acerca de las relaciones entre el periodismo y la literatura, así como los libros y sobre todo los textos publicados en revistas físicas y electrónicas de algunos cronistas latinoamericanos fueron utilizados como fuentes primarias, entre otras fueron consultadas las antologías de las revistas Gatopardo y Soho, así como las publicadas por la Fundación Nuevo Periodismo, de igual manera, las de grandes editoriales y editoriales independientes. También el trabajo teórico de Carlos Barrera y Albert Chillón.

Asímismo se utilizó la literatura comparada, entendida como la aplicación de un método comparativo, muy útil para entender el surgimiento y desarrollo de ciertas tipologías textuales. La comparación muestra un interés estructuralista, analiza aportes a la estética y la forma, a la estructura; hace un análisis de tipo lingüístico, semiótico, semiológico.

La literatura comparada, alejada de la simple mirada a las literaturas nacionales, permite el estudio de las interrelaciones entre la literatura y demás artes. Este análisis es fundamental, ya que posibilita el detenerse en literaturas que no han sido consideradas canónicas y tiene en cuenta formas de discurso antes olvidadas o no estudiadas por no estar dentro del canon.

Esta actitud abre grandes posibilidades, ya que permite ampliar los horizontes de análisis y ayuda a entender las conexiones que ha tenido la literatura con otras formas de producción artística, de comunicación o de discurso, que pueden ser interliterarias (lingüísticas) o intermediáticas (no lingüísticas). Es decir, que se dan relaciones al interior y al exterior del sistema. La literatura comparte con otras formas de arte, desde su esencia lingüística hasta otros componentes que van más allá de lo instrumental y logran llegar al plano de los medios o los significados.

Para analizar la importancia que han tenido las revistas en el desarrollo de la crónica latinoamericana se realizaron una serie de viajes y entrevistas en profundidad con diferentes actores del mundo periodístico, editorial y académico; cronistas, editores y estudiosos fueron consultados para entender la importancia de las revistas en el desarrollo de la crónica. Esa consulta a fuentes primarias de diversa índole y ubicadas en diferentes países en los que habita la crónica le da validez y novedad a este trabajo. 
El análisis de las crónicas leídas, contrastado con las opiniones recogidas de autores, editores y estudiosos, involucrados en el mundo de la crónica latinoamericana actual dan un panorama, que posteriormente fue contrastado con el Nuevo Periodismo estadounidense. En la reflexión se encontraron grandes similitudes y profundas diferencias. El presente artículo da cuenta de la comparación, así como un panorama de las revistas en América Latina y su importancia en la consolidación de un género literario y periodístico de una gran vitalidad en el continente: la crónica latinoamericana actual.

\section{EL PAPEL DE LAS REVISTAS EN EL DESARROLLO DE LA CRÓNICA LATINOAMERICANA ACTUAL}

La eclosión del Nuevo Periodismo se dio en las décadas de los sesenta y setenta en los Estados Unidos, cuando los principales exponentes se convirtieron en una especie de estrellas de rock literarias que impartían charlas en universidades, llenaban auditorios y vendían muy bien sus libros. Algo similar sucede en la actualidad con los cronistas latinoamericanos, pero a diferencia del último punto, hay unos autores célebres en los diferentes países de América Latina que ofrecen conferencias y talleres y han comenzado a tener notoriedad en España, pero sus libros no se venden tanto.

Si bien en las décadas del sesenta y el setenta coincidió una gran generación de autores en Estados Unidos, el fenómeno no surgió de manera espontánea y los gérmenes habría que rastrearlos muy atrás. Pensar en escritores como Dickens y Balzac, en la sátira de Jonathan Swift, en la influencia de Joseph Pulitzer, de Jack London y George Orwell. También se debe analizar el trabajo que hicieron para diferentes revistas periodistas como John Hersey con textos como Joe ya está en casa o la emblemática Hiroshima, publicada en un número completo de The New Yorker y considerada por muchos estudiosos como la crónica más importante del siglo XX. De igual manera, el trabajo de Lilian Ross, especialmente su texto Picture, publicado originalmente en The New Yorker y que ha sido reconocido como influencia en la obra de otro personaje importante para el germen del Nuevo Periodismo: Truman Capote y su texto A sangre fría, un relato de 135.000 palabras publicado en The New Yorker, en 1965. De igual forma, es importante el trabajo de revistas como Esquire, que publicaba a escritores como Ernest Hemingway, John Dos Passos o Scott Fitzgerald. 
Fue en Esquire donde con mayor celo se creó un departamento de investigación y un riguroso sistema de verificación de datos, que le da un carácter implacable al periodismo de Estados Unidos y que ha sido replicado en América Latina por revistas como Etiqueta Negra o Piauí.

Dentro del llamado Nuevo Periodismo fue fundamental el trabajo de escritores como Norman Mailer con textos como Superman va al supermercado y el de Gay Talese, que aún hoy sigue publicando libros que se han convertido en referencia obligada, de Jimmy Breslin, de Thomas Wolfe, de Joan Didion, de Hunter S. Thompsom, de John Sack, en especial sus contribuciones acerca de la guerra de Vietnam, en textos como $M$, publicado en Esquire o los Despachos de guerra, de Michael Herr, todos patrocinados y publicados inicialmente por revistas, sin las que no hubiera sido posible un desarrollo tan grande del periodismo literario en Estados Unidos.

Así como para el Nuevo Periodismo el papel de las revistas fue fundamental, en el caso latinoamericano no se podría hablar de la crónica sin la aparición de una serie de revistas que han logrado despertar la atención de varios cronistas, que han seducido a talentos consagrados y han descubierto nuevas voces, que le han conferido el aire de vitalidad con el que hoy cuenta. Revistas como: Soho, Donjuan, El Malpensante, Diners, Cromos, Aracadia y Universo Centro (Colombia), Gatopardo, Emeequis, Proceso, Expansión, Chilango, Etcétera, Milenio, Glamour, Letras Libres y Travesías (México), Séptimo Sentido de La prensa Gráfica y Sala Negra de El Faro.net (El Salvador), Etiqueta Negra (Perú), Pie Izquierdo (Bolivia), Sábado, Fibra, Paula, The Clinic y Bnamericas (Chile), Hecho en Buenos Aires, Brando, La Pulseada, Orsai, Miradas al Sur y Soy de Página 12, Babel, Debate, Anfibia, Latido, El Puercoespín, Lamujerdemivida y Cosecha roja (Argentina), Marcapasos, Plátano Verde, Exces y Zero (Venezuela), Rolling Stone, Mundo Diners (Ecuador), Esquire, Piaui (Brasil), Frontera D, Babelia de El País y Quórum (España), han permitido que se evidencie una fortaleza de la crónica latinoamericana actual; así lo confirma el editor colombiano Camilo Jiménez:

La crónica es un género de revistas, las revistas son las que tienen el tiempo, la atención, el interés por publicar historias extensas, investigadas. La crónica es un género costoso. Hay un supuesto auge del género, pero el medio que lo transporta no está en auge. (Jiménez, 2013: entrevista)

El auge del que habla Jiménez tiene que ver con el interés que la crónica ha despertado en los últimos años. Se han publicado antologías en diferentes 
países de Europa, el primero de ellos fue España, y los autores tienen columnas permanentes en los diarios más relevantes; por ejemplo Leila Guerriero publica en El País y Alberto Salcedo Ramos, en El Mundo; dan talleres y conferencias, se publican artículos y estudios acerca de la temática. El panorama de la crónica ha cambiado y, en buena medida, tiene que ver con las revistas; pero falta mucho, porque son los esfuerzos individuales los que han permitido que las revistas sobrevivan en los diferentes países.

El panorama de las revistas es bastante disímil, varias de las que mencionamos ya están muertas, otras padecen un precario estado de coma y son pocas las que gozan de una buena salud, eso sí, dentro de este ecosistema surgen nuevas iniciativas que han permitido una continuidad. El editor colombiano Mario Jursich piensa que siempre ha sido así, las revistas tienen unos ciclos bastante definidos:

Siempre ha sido difícil, no estamos descubriendo nada nuevo, las revistas nacen y mueren. La verdad es que casos como la revista $E l$ Malpensante son la excepción, lo normal es que duren tres o cuatro años muy activos, muy brillantes y después de eso la revista sucumbe por diferentes problemas. (Jursich 2013: entrevista)

Nacen revistas y mueren revistas, ha sido una dinámica más o menos constante, aunque hay algunas personas que son poco optimistas frente al futuro de este tipo de publicaciones. La editora chilena Andrea Palet piensa que las revistas, por lo menos en papel, desaparecerán pronto:

[C]reo que su existencia es milagrosa, en serio lo pienso, creo que las revistas se van a acabar. La idea de revista es un almacén de cosas, pero en la red ya existe un almacén de cosas, no sujeta por el marco de una revista. (Palet 2014: entrevista)

Para algunos, el mercado ha traído una serie de cambios y el panorama de las revistas no es el mismo que el de hace algunos años. Paradójicamente, internet, que ha servido como medio de difusión, también se ha convertido en una competencia desleal; no obstante, el editor colombiano Diego Garzón piensa en internet como una forma de complementar el trabajo:

Estamos en una coyuntura interesante, ver cómo están tratando de reinventar el negocio. Mucha gente lee en internet, vienen generaciones a las que el papel no les interesa. Yo sí creo que la apuesta es hacer 
periodismo de calidad. Si alguien quiere leer una crónica de 30 mil caracteres que la lea. (Garzón 2014, entrevista)

Otra de las dinámicas que ha cambiado es la visión que tienen los periodistas: antes estaban ligados al nombre de un medio de comunicación y no podían sobrevivir sin él. En los últimos años, cada vez más, esos periodistas deciden apostar a un proyecto personal, como es el caso del periodista ecuatoriano José María León Cabrera, quien creó su propio medio Gkillcity:

[E]l periodista ha ido dejando el papel secundario que había adquirido en muchos medios y poco a poco se ha ido dando cuenta de que o trabaja solo, y puede vivir de trabajar solo, o que puede poner tus propios medios. (León 2013: entrevista)

Estas iniciativas son muy valiosas y han dinamizado el mercado editorial, han dado un nuevo aire que refresca y le dan oportunidad a nuevos talentos. No obstante, siguen siendo las revistas tradicionales las que con más vehemencia han patrocinado el trabajo de cronistas que han logrado un reconocimiento. Esas iniciativas después se han transformado en libros como La eterna parranda, de Alberto Salcedo, o Frutos extraños, de Leila Guerriero, que recogen el trabajo que han realizado por décadas y también son el sustento de trabajos antológicos de varios autores, como las famosas Antología de la crónica latinoamericana actual o Mejor que ficción, publicadas en España.

\section{LAS REVISTAS MÁS IMPORTANTES PARA EL DESARROLLO DE LA CRÓNICA LATINOAMERICANA ACTUAL}

Hay algunos casos destacados que vale la pena analizar para entender el panorama de las revistas latinoamericanas que publican periodismo narrativo, periodismo bien investigado, escrito y entretenido. Primero habría que mirar una publicación estadounidense a la que las diferentes revistas latinoamericanas miran como ejemplo. The New Yorker es una revista que nació en 1925 y publica críticas, ensayos, reportajes de investigación y ficción. Es un referente obligado, las revistas latinoamericanas la ven como el punto al que hay que llegar, la toman como modelo. Desde sus implacables chequeadores de datos, hasta la rigurosidad de sus investigaciones y la dinámica de los escritores que publican en sus páginas. El cronista venezolano Boris Muñoz es colaborador habitual: 
Mis entregas son revisadas exhaustivamente y verificadas en lo más minucioso y bueno uno está acostumbrado a trabajar con esa rigurosidad que a mí me parece muy positiva, pero que tiene su lado incómodo, porque mientras uno piensa que el tema sale hoy, no sale hoy sino dentro de tres días dependiendo de cuáles son las prioridades del medio. (Muñoz 2013: entrevista)

Aparte del conocimiento de los textos que se pueden consultar en la versión electrónica y que han llegado en formato libro, The New Yorker ha significado una influencia en el periodismo de América Latina a partir del trabajo de dos colaboradores habituales que se convirtieron en maestros, a través del trabajo de la Fundación Nuevo Periodismo (fundada por Gabriel García Márquez); se trata de Alma Guillermoprieto y de Jon Lee Anderson. Ellos enseñaron, a través de diferentes talleres, ese método de trabajo que aprendieron, en buena medida, en The New Yorker.

Si hay algo en lo que coincide la mayoría de cronistas, editores y estudiosos de la crónica es en que la Fundación Nuevo Periodismo Iberoamericano le ha dado un impulso a la crónica, a los cronistas, a los maestros. Le ha conferido un estatus a un género que había sido visto como menor, ha consolidado la figura del cronista y del maestro de cronistas.

Una de las revistas más exitosas del continente es la colombiana Soho, que nació en 1999 y se ha consolidado como un modelo de negocio rentable (algunos números han vendido más de 1 millón de ejemplares). Soho tomó como referencia la revista estadounidense Play Boy, que combinaba fotos de mujeres hermosas y periodismo bien logrado. La calidad de Soho ha sido disímil, en ocasiones ha presentado textos de largo aliento y con notable aire literario; en otras ocasiones ha abusado del periodismo de suplantación, con ejercicios facilistas que no van más allá de lo anecdótico. Le han apostado a las historias extensas, como La eterna parranda de Diomedes, un perfil que el cronista colombiano Alberto Salcedo Ramos trabajó durante años, y también Seis meses con el salario mínimo, del escritor colombiano Andrés Felipe Solano. Su director, Diego Garzón, habla acerca de la filosofía de Soho:

La gente escucha Soho e inmediatamente piensa en las modelos [...] obviamente es innegable que ese es un punto de entrada directo al público masculino pero si solo fuera eso la revista no tendría el éxito que tiene. Ahí es donde entra el verdadero éxito de Soho que es el planteamiento de los temas. (Garzón 2014: entrevista) 
Una de las características principales de la revista es la preparación de los temas que normalmente son concebidos desde la dirección y son asignados a los autores que consideran más adecuados para escribirlos. Para Soho son muy importantes las "firmas", el nombre del autor que acompaña el artículo:

Es una revista que se concibe desde la edición, desde antes de que lleguen los textos está muy estructurada, por eso es que hacemos muchas revistas temáticas. Los temas son muy pensados y al encargarlo a unas firmas reconocidas uno espera un muy buen producto. (Garzón 2013: entrevista)

Aparte de la calidad de los textos y las fotografías, Soho Colombia ha presentado un modelo de negocio exitoso, con publicidad que llena un buen número de páginas (en este apartado también han tratado de innovar y permanentemente incluyen publicidad interactiva), un buen número de suscriptores y muchas revistas vendidas en la calle, por eso han exportado el modelo:

Ha sido muy positivo, el último caso es Soho México, la alianza es con Televisa que es la gran casa de publicaciones en México [...] La experiencia en Soho ha sido muy buena porque Ecuador ya lleva por lo menos 10 años, a Argentina le ha ido muy bien, Perú también; pero ha sido muy interesante que el centro, que el tronco es Soho Colombia, porque hay mucho contenido que podría leerse en cualquier país. (Garzón 2014: entrevista)

Así como en el caso del Nuevo Periodismo, el nombre de muchos de los grandes cronistas latinoamericanos ha estado ligado a Soho. Por ejemplo, la época más brillante de Alberto Salcedo Ramos se ha dado en esta publicación, que lo tiene como uno de sus autores insignia; en Soho ha publicado algunos de sus textos más representativos, como La travesía de Wikdi, ganador del premio Ortega y Gasset de periodismo, o Un país de mutilados, ganador del premio de la SIP; también han publicado textos de grandes firmas como: Martín Caparrós, Leila Guerriero, Juan Pablo Meneses, Daniel Riera y un largo etcétera. No obstante, desde la salida de la dirección de Daniel Samper Ospina, la revista ha tenido un declive en su calidad, algunas grandes firmas que antes publicaban regularmente no han vuelto a hacerlo y ya no se paga tan bien a los colaboradores.

Soho Ecuador es una revista que circula desde el 2002, con una periodicidad mensual, dirigida, principalmente, al público masculino y que ha ganado varios premios nacionales de periodismo gracias a las crónicas que publican 
autores como Juan Fernando Andrade y Esteban Michelena. Su editor, Carlos Andrés Vera, habla del trabajo que realizan:

Es una revista frívola pero no estúpida. No es una revista de arte, de literatura, pero es una revista que les gusta a los artistas. Si Soho fuera una revista intelectual la leerían solamente los intelectuales, pero la leen los intelectuales y los no intelectuales. (Vera 2013: entrevista)

Según Carlos Andrés Vera, Soho Ecuador tiene 8 mil suscriptores y se venden 5 mil revistas más en la calle, muy lejos del millón de ejemplares que han vendido varias ediciones de Soho Colombia:

en Ecuador Soho es casi la única revista que hace crónica. Los ecuatorianos no están acostumbrados a consumir masivamente este tipo de contenidos. Eso también influye en el tipo de crónicas que haces porque no tienes plata para financiar crónicas de largo aliento. No le puedes pagar a un periodista un sueldo de cuatro meses para que se meta de cabeza en un tema. (Vera 2013: entrevista)

Soho Ecuador ha tenido varios momentos difíciles; el primero de ellos fue cuando la Constitución prohibió a los banqueros que tuvieran medios de comunicación. Fidel Egas es el dueño del Banco Pichincha, uno de los más importantes de Ecuador, y también de Dinediciones, antiguo propietario de Soho. Con el cambio en la Constitución, Egas tuvo que vender Soho y la revista se quedó sin su principal mecenas, que ponía dinero incluso cuando no daba rentabilidad. Otro gran problema se dio con una ley de comunicación que obliga a que el $80 \%$ de la publicidad debe ser producida en Ecuador. Grandes marcas como Rolex, que antes pautaba en Soho, tienen como imagen a estrellas como Leonardo DiCaprio, y para cumplir la ley hubieran tenido que producir las fotografías en Ecuador, con fotógrafos, iluminadores y casi todo el personal ecuatoriano; por eso han cancelado la publicidad o la han dejado en pausa.

Piauí es una revista mensual que se publica en Brasil, nació en octubre de 2006 y es una de las mejores revistas de periodismo narrativo del continente. Si el referente es The New Yorker, Piaui es la que más se aproxima a su exigencia, con chequeadores de datos, tiempo para escribir y buenos periodistas que se encargan de las historias. Nació bajo el amparo del cineasta João Moreira Salles. Daniela Pinheiro, periodista de Piauí expresa cómo es la revista por dentro: 
Surgió porque el dueño de Piaui es un hombre muy rico que tenía este sueño de hacer periodismo en Brasil como el periodismo que leyó en toda su vida en Estados Unidos. Logramos eso porque es un hombre muy, muy rico y también es muy ligado con temas culturales, de educación, no es un sponsor, como la persona que solo da plata. Es muy interesado en cómo el periodismo puede cambiar la sociedad y a la gente. (Pinheiro 2013: entrevista)

En Piauí se trata de hacer periodismo de investigación y periodismo literario de alta calidad. Es una publicación que ofrece unas condiciones muy favorables para los escritores, brinda un panorama muy diferente al del resto del mercado editorial:

son dos meses con una persona, cuatro meses con un tema. Yo personalmente no voy a la oficina, escribo siempre desde casa y estoy siempre viajando, tengo contacto permanente con el editor. Después del mes vamos al cierre y ahí sí estoy en la oficina. Piaui es una isla. (Pinheiro 2013: entrevista)

Así como en Brasil hay una revista de reconocida excelencia periodística, en Perú hay una revista que también ha procurado hacer de la crónica y el perfil géneros referentes. Con la visión también puesta en los estándares de The New Yorker, Etiqueta Negra nació en el 2002 y se convirtió en un punto a imitar para las demás publicaciones; se transformó, además, en una escuela para cronistas y para editores que se formaron bajo sus estrictos métodos de trabajo. El método es tan riguroso y se aplican unas pautas tan precisas que ha habido algunas críticas frente a la uniformidad en los textos de Etiqueta Negra,los han acusado de una industrial similitud de las voces que publican, aunque hay otros autores que tienen su opinión, como es el caso de Marco Avilés, quien fue director y editor de Etiqueta Negra:

Es, salvando las distancias, lo que los gringos critican en el New Yorker, que también es una revista de editores maniáticos y donde los artículos muchas veces se parecen. No puedo decir que eso es mentira, es verdad, hay un estilo que la revista impone a los autores. Hay algunos autores que todavía no tienen una voz y ese estilo que la revista impone se nota de forma más evidente, pero otros que ya tienen más recorrido no adoptan tanto esa voz, si no hacen prevalecer la suya. Caparrós y Villoro, cuando escriben en Etiqueta, siguen siendo Caparrós y Villoro. (Avilés 2013: entrevista) 
Etiqueta Negra publica crónicas, reportajes, perfiles, ensayos, columnas, y por sus páginas han desfilado algunos de los grandes autores de la no ficción en América Latina, Estados Unidos y Europa, pero además ha servido para dar a conocer el trabajo de jóvenes talentos del periodismo narrativo en América Latina y así lo expresa su ex editora Elda Cantú:

ha hecho una escuela tanto de jóvenes como de consagrados que han aprendido a trabajar con un método, a sujetarse un poco a chequers, a publicar historias sobre cosas que nadie estaba pensando y que después te das cuenta que tienen interés y que a la gente le gusta [...] ha formado también a cronistas jóvenes, les ha prestado la oportunidad de hacer historias largas. (Cantú 2013: entrevista)

El hecho de dar cabida a nuevos autores tiene un fin de enseñanza, pero también responde a las necesidades de un mercado en el que las grandes plumas tratan de cobrar lo que merece su trabajo y las revistas no tienen un músculo económico suficiente para pagarles. Inicialmente Etiqueta Negra pagaba muy poco a sus colaboradores a los que denominó cómplices en la idea de construir la revista de periodismo narrativo que siempre habían querido leer:

hay autores de los que quisiéramos publicar todos los meses, pero no tenemos recursos y nos avergonzaría llamarlos cada mes para pedirles algo, entonces apostamos por gente que tiene ganas de hacer cosas, pero que no solo tiene ganas sino que además tiene algo que decir. (Cantú 2013: entrevista)

Por las páginas de Etiqueta Negra, aparte de autores consagrados como: Martín Caparrós, Jon Lee Anderson, Susan Orlean, Carlos Monsiváis o Juan Villoro, ha nacido una generación de cronistas muy potente y algunos de los textos más importantes del periodismo narrativo en América Latina. En Etiqueta Negra publicó Juan Villoro La casa blanca del fútbol, Julio Villanueva Chang escribió Un extraterrestre en la cocina, Leonardo Faccio comenzó a construir su gran perfil sobre Lionel Messi, que después se convertiría en libro; en Etiqueta Negra publicó Juan Manuel Robles Cromwell, el cajero generoso, Sergio Vilela escribió acerca de Zoe Koplowitz, Gabriela Wiener escribió Dame el tuyo, toma el mío, Daniel Titinger y Marco Avilés escribieron El imperio de la inca. En Etiqueta se fue configurando buena parte del material con el que se construirían las antologías de periodismo narrativo, los trabajos que, además, serían ganadores y finalistas de los premios más importantes 
del periodismo latinoamericano y español, incluso sería la casa de algunos de los autores más prometedores de la actualidad como Joseph Zárate o Eliezer Budasoff.

Otra revista fundamental para el periodismo latinoamericano es Gatopardo, que nació en Colombia, fue fundada en 1999 por Miguel Silva y Rafael Molano. Desde 2006 es editada en México por Editorial Mapas. Inicialmente combinó el trabajo de grandes firmas con el de nuevos cronistas del continente:

nació, sobre todo, al ver el desolador panorama que existía en nuestra región, con grandes excepciones personales. Ante la ausencia, que yo sepa, de otros medios interesados en el asunto, fuimos pioneros en emocionar a lectores y periodistas ante la idea de leer y escribir buenas historias. Ahora la crónica tiene sentido para muchas más revistas. (Molano 2014: web Gatopardo)

La versión colombiana de Gatopardo apostó de manera fuerte por encontrar nuevas voces. "Empezaron a buscar por todo el país. Iban a las regiones, que eso nunca pasaba, todo se quedaba en Bogotá y empezaron a fichar gente". (Vallejo 2013: entrevista)

el Gatopardo colombiano en el que todo el mundo quería publicar, no importaba que no te pagaran. Pagaron muchísimo dinero al principio, luego ya no; pero fue la revista que salió más a la luz para decir aquí se pueden contar historias. (Almazán 2013: entrevista)

En la nueva etapa están más enfocados en lo mexicano. Desde México se produce la mayor parte del contenido que circula en la revista y se ha convertido en un espacio de denuncia, en un mecanismo para que la gente conozca lo que está sucediendo. "Gatopardo puede servir para contar las historias que no están contando los medios o que las están contando por encima”. (Almazán 2013: entrevista):

Comencé a trabajar en Gatopardo casi desde sus inicios. Me han tocado las duras y las maduras. Estuve allí en la época de su nacimiento, la de Miguel Silva y Rafael Molano, cuando la revista deslumbró a América Latina y uno, como editor en México, podía sentarse a planear textos con Carlos Monsiváis y Juan Villoro. Me tocó mirar cómo el modelo de negocios latinoamericano se agotaba y la revista tuvo que enfocar sus baterías en mi país, como una estrategia para sacarla a flote. La revista dejó de circular en América Latina, pero ganó mucha presencia en México, donde casi nadie la conocía. Los 
lectores latinoamericanos volvieron a encontrarla en la web: antiguos colaboradores regresaron y Gatopardo se tropezó con los cronistas locales que, entre otras cosas, comenzaron a narrar en sus páginas el horror de nuestra guerra contra las drogas. (Osorno 2014: web Gatopardo)

Gatopardo es otra de las revistas que reúne mayor cantidad de premios, de textos en antologías. En Gatopardo, Alejandro Almazán publicó su texto Cartas desde la Laguna, ganador del premio García Márquez de periodismo (el más importante del continente); Leila Guerriero publicó en Gatopardo, El rastro en los huesos, también ganador del premio García Márquez. De hecho, desde el mismo Gatopardo se han publicado tres antologías de crónicas con los mejores textos que han circulado en la revista.

El Malpensante nació en 1996 como una revista literaria; en esta publicación conciben al buen periodismo como una forma de literatura y por eso le han dado cabida. Fue una iniciativa de Andrés Hoyos Restrepo y Mario Jursich Durán. El nombre fue tomado de un libro de aforismos escrito por Gesualdo Bufalino, que fue traducido por Jursich para la Editorial Norma, de Colombia. Además de la revista, han realizado festivales en los que han reunido a grandes escritores y periodistas:

nos auto definimos como una revista literaria y ese es nuestro campo de acción, pero consideramos ese tipo de periodismo como parte de la literatura y por lo tanto yo no me siento como una revista periodística sino como una revista literaria, que ha ido ampliando su campo de acción precisamente por lo que te acabo de decir, porque la literatura también se ha vuelto documental. (Jursich 2013: entrevista)

La etapa inicial de Alberto Salcedo Ramos está muy ligada a la revista El Malpensante, donde publicó el perfil El testamento del viejo Mile, finalista del premio Cemex (hoy premio García Márquez); también Martín Caparrós publicó Pole, Pole de Zancíbar a Tanganica; Juan José Hoyos escribió Un fin de semana con Pablo Escobar, todos reconocidos en premios y antologías.

Piauí, Etiqueta Negra, Soho, El Malpensante y Gatopardo configuran el panorama de las revistas más reconocidas, con textos premiados y en antologías, pero no son las únicas, hay una serie de iniciativas que han ayudado a configurar ese ecosistema favorable para la crónica latinoamericana actual.

La revista Dossier es una publicación académica de la Universidad Diego Portales, de Chile, en la que se concentra en el periodismo y la literatura, que le da cabida a entrevistas, crónicas y estudios sobre la obra de varios cronistas: 
es una revista académica que trata de no ser académica $[\ldots]$ cuando encargamos textos, no pensamos en crónicas, sino que pienso en temas y lo que me entregan suele ser una crónica pero podría ser otra cosa. (Palet 2014: entrevista)

The Clinic es un semanario que surgió en 1998, mezcla la sátira y el humor político con la crítica social. Carolina Ethel, en La invención de la realidad (2008), dice que "surgió con el ánimo confeso de dar palos al ex dictador Augusto Pinochet y que con su espíritu satírico se ha situado como la más leída en Chile" (Ethel 2008: s.p.). También ha sido un escenario propicio para el periodismo narrativo, aunque no de la forma tradicional:

The Clinic lo que demuestra es que las posibilidades de hacer periodismo son muchas, se puede hacer con poemas, se puede hacer con dibujos, se puede hacer con collages, se puede hacer con cuentos, con literatura, con crónicas, etc.; la manera de informar y plasmar la realidad no es solo una y yo creo que esa multiplicación de posibilidades es lo que a nosotros nos interesa mostrar. (Fernández 2013, entrevista)

Cometa fue todo un proyecto editorial y de comunicación peruano que tuvo una revista; surgió gracias a la iniciativa del periodista Marco Avilés y el fotógrafo Daniel Silva. En Cometa produjeron libros, revistas, y asesoraron empresas con historias en varios formatos: crónicas, documentales, reportajes, etc.:

Me fui de Etiqueta a hacer freelance y había un país completamente distinto para hacer freelance, había más oportunidades, había más dinero; pero a la vez yo ya no me sentía con tanto oxígeno para librar las batallas de los freelancers [...] Se nos ocurrió la idea de hacer una empresa, empezar a crecer. (Avilés 2013: entrevista)

Buensalvaje es una revista peruana de literatura creada en 2012, que se distribuye en forma gratuita, tiene secciones de ficción, no ficción, poesía, columnas y artes visuales. El proyecto es liderado por el editor y periodista Dante Trujillo:

Hablamos de la mejor publicación periodística que podamos lograr con un presupuesto bajísimo. La que siempre quisimos en el micro, en la cama, en el baño, en la playa, en el parque. Una que nos diga cosas que también queremos saber, que apueste por algo más que lo inmediato, lo chato, lo poco o mal entendido. Una que estimule el debate sobre lo que sucede con las letras en nuestro país y el mundo. 
Que nos ponga en contacto con Latinoamérica, con nuestros vecinos, nuestra lengua. (Web de Buen Salvaje)

La revista Travesías es una iniciativa mexicana creada por Guillermo Osorno en el año 2001, que surgió con el lema de "inspiración para viajeros". Tiene un archivo de crónicas en el que se pueden encontrar textos de algunos de los mejores periodistas narrativos de América Latina:

Nos gusta descubrir el otro lado, en nuestra propia ciudad o a miles de kilómetros de distancia. Por eso, pensamos que ser viajero es una actitud: una manera de ver, experimentar y vivir el mundo, ya sea en los laberínticos hutongs de Beijing o en las caóticas calles del centro de la ciudad de México. Lo que buscamos es disfrutar las ciudades y los destinos como los viven sus habitantes. (Web de Travesías)

Radar es un semanario dominical, suplemento cultural del diario Página 12, editado por el cronista Juan Boido. En él se pueden encontrar artículos, ensayos, columnas, críticas en torno al cine, la literatura, el arte, el teatro y las tendencias culturales argentinas.

Letras libres es una revista de crítica y creación que circula cada mes, tiene una edición mexicana y una española. Fue creada y es dirigida por el escritor Enrique Krauze, publica crónicas, reportajes, poemas, ficción, ensayos, críticas y otros géneros.

Orsai fue una revista que comenzó como un blog en el que Hernán Casciari publicaba cuentos dirigidos a una comunidad que fue creciendo. Después se convirtió en una revista que evitó los intermediarios y publicó crónicas, reportajes, ensayos, historietas y textos literarios. Orsai es un ejemplo para muchos jóvenes que ven en la revista un aliento para los proyectos propios. La revista dejó de circular en 2014, pero ha recuperado su circulación.

Marcapasos es una revista venezolana creada en 2007; inicialmente fue impresa y luego, en 2008, se mudaron al mundo digital; su idea era reivindicar la crónica desde Venezuela, en un momento difícil para la libertad de expresión. El proyecto fue liderado por Liza López Vinogradoff, Sandra Lafuente Portillo y Victoria Araujo:

Surgió como una publicación dedicada a la crónica en un momento un poco menos oscuro, justamente. Un poco nada más. Ya se anunciaba la debacle presente. Los medios tradicionales todavía funcionaban en sus estructuras y los periodistas que trabajaban dentro de ellos pedían a gritos más libertad y espacio para interpretar el momento y 
contar historias, apartándose de la dictadora agenda de la polarización. La revista se posicionó como una referencia modesta de la crónica en la región, aunque en el ámbito local no pudo superar la agenda dominante -donde también hay espectáculo y culto al cuerpo y a la silicona-y por tanto, no pudo conquistar a los anunciantes ni pudo sostenerse. (Lafuente 2014: entrevista)

Rolling Stone es una revista que se publica en distintos lugares de Latinoamérica y en España; se enfoca en el mundo de la crítica musical, también incluye crónicas y reportajes. Se edita en formato papel y también en digital. La versión argentina también ha tenido gran relevancia y ha publicado a grandes firmas, como Josefina Licitra, quien escribió allí su texto Pollita en fuga, ganador del premio Cemex.

Lamujerdemivida nació en Buenos Aires en mayo de 2003. En cada número presenta un dossier dedicado al tema de la portada y otros géneros escritos por autores consagrados y nuevas voces de la narrativa argentina. Circula de forma trimestral.

Una de las experiencias más significativas es la de El Faro, un portal salvadoreño fundado en 1998 por Carlos Dada y Jorge Simán. El objetivo inicial era hacer buen periodismo, algo que veían escaso en El Salvador. Desde su fundación han sido un referente en la investigación del crimen organizado, la violencia, la corrupción; así lo cree el periodista salvadoreño Carlos Dada:

El Faro no tiene oficina de recursos humanos, ni un sistema de contratación. La mayor parte de la gente que trabaja allí empezó en aquella época donde nadie cobraba, entonces ese compromiso se crea y esa pasión fue lo que le dio personalidad al Faro y por eso se quedaron cuando se les pudo pagar. Creo que tuvimos la suerte de encontrarnos con una generación de periodistas extraordinaria. (Dada 2013: entrevista)

El Faro fue ganador del premio García Márquez a la Excelencia en 2016. Después de afrontar con éxito la experiencia de El Faro, decidieron crear en 2011 Sala Negra, un proyecto coordinado por el periodista Óscar Martínez, que tiene como propósito dar cuenta de la violencia en Centroamérica:

A finales de 2010 El Faro decidió que había demasiadas preguntas sin responder acerca de por qué Centroamérica era -y es- una de las regiones más violentas del mundo [...] A partir de 2011, luego de salir del laberinto del financiamiento, Sala Negra arrancó como un 
proyecto de cobertura de la violencia en cuatro países: Nicaragua, Honduras, El Salvador y Guatemala. Con tres líneas de trabajo: cultura de la violencia, crimen organizado y pandillas y cárceles. (Martínez 2013: entrevista)

Otra gran experiencia de periodismo en internet es la revista ecuatoriana Gkillcity, fundada por José María León Cabrera, un periodista con visión que entendió que hay una crisis de los medios tradicionales, pero no del periodismo como tal y que era necesario responder a la demanda de historias en un país como Ecuador, que tiene unas leyes muy fuertes para el control de la prensa. Para esta investigación se realizó un viaje a Guayaquil, Ecuador, con el fin de conocer la experiencia:

Yo quería hacer un medio, quería fundar una revista. Cuando íbamos a sacar el primer número, con mi socio, nos dimos cuenta de que teníamos que empeñar la casa, el carro, la mamá, el tío, la abuela, todo, hasta el perro [...] Un día estaba viendo un programa y salió la noticia de que un Airbus de US Airways había logrado amarizar en el río Hudson y el piloto había salvado a todos los tripulantes y a los pasajeros. La foto que yo vi en ese momento, que era la foto en la que estaba el avión metido en el agua a unos pocos metros, la había tomado un tuitero y luego me metí a ver CNN y la foto que ellos tenían era muy lejos, entonces el avión se veía chiquitito. Entonces dije, si un flaco con un teléfono de 300 dólares, le ganó la primicia, la mejor foto y la noticia a la CNN, con toda la plata, los recursos humanos y técnicos que tienen, entonces hay algo, podemos hacer un buen medio con pocos recursos y hacerlo digital. (Cabrera 2013: entrevista)

Una de las experiencias más significativas de los medios de comunicación en internet es la revista Anfibia, que publica crónicas y relatos de no ficción. Anfibia ha hecho grandes apuestas, como haber nacido desde una universidad, la Universidad Nacional de San Martín. En ella han tratado de que dialoguen el discurso académico con la buena prosa, por eso buscan especialistas en los temas que trabajan para que asesoren el trabajo de los cronistas. El cronista argentino Cristian Alarcón es el líder de este proyecto:

me parece que junto con otras revistas que publican crónicas Anfibia da espacio a textos largos que no tienen cabida dentro de diarios o agencias de noticias [...] Por otra parte, abordamos temas de ciencia, en ensayos y crónicas, tratando de que la divulgación suceda y que no 
sea sólo un concepto socialmente bien visto (no sé si lo conseguimos, pero doy fe de que la intención existe). (Alarcón 2013: entrevista)

Anfibia nació en mayo de 2012 y desde el principio ha apostado por experimentar con los formatos digitales; es consciente de que es un medio en internet y de las demandas de los lectores:

lo digital nos acerca a la audiencia y nos obliga a tenerla en cuenta, a escucharla, porque está allí. Está en un programa que nos señala en este instante cuánta gente está leyéndonos, de qué países y ciudades son, de qué edades, y es tal el caudal de información que te brinda el hecho de existir en Internet que es imposible que tu identidad no se construya en relación al otro. (Alarcón 2013: entrevista)

En marzo de 2010 se fundó en Tijuana, México, Diez4, una revista que empezó en formato impreso y se mudó a la red y que ahora también ofrece talleres de periodismo digital y narrativo. Tiene un archivo digital donde se pueden consultar muchas de las historias que ha publicado.

La revista Replicante es una revista cultural mexicana, que inicialmente se publicó impresa y que ahora tiene una plataforma digital en la que se pueden encontrar contenidos como: textos de académicos, ensayos filosóficos, crónicas periodísticas, crítica literaria y cinematográfica; crónicas y reflexiones en torno a las nuevas tecnologías, el cómic, el video, la televisión, la música, el diseño y todo lo que se relacione con internet.

Prodavinci es un sitio web venezolano en el que se propende a la circulación de ideas en diferentes áreas, como la economía, los negocios, las artes y la ciencia. Constantemente se incluyen textos de grandes periodistas e intelectuales y cronistas, como Boris Muñoz.

El Puercoespín fue una revista digital creada en 2010 por los periodistas argentinos Gabriel Pasquini y Graciela Mochkofsky, que desde el principio apostó a compartir textos de periodismo y literatura, a las colaboraciones y las traducciones de textos de largo aliento, así como a las crónicas y los reportajes. Para desarrollar y montar el sitio web, Gabriel Pasquini aprendió en manuales y con el consejo de diseñadores. Desafortunadamente, en julio de 2013, su creadora Gabriela Mochkofsky anunció su cierre.

Plaza Pública es otra iniciativa de periodismo online que nació en una universidad; fue fundada el 22 de febrero de 2011 por la Universidad Rafael Landívar. Su objetivo es hacer periodismo de profundidad en Guatemala. Para conseguirlo utilizan géneros periodísticos como la crónica, el reportaje, 
el perfil y la entrevista. Martín Rodríguez Pellecer y Enrique Naveda han liderado el proceso de un medio que procura el análisis, las investigaciones y los debates desde la Ciudad de Guatemala, en Centroamérica. Aparte del apoyo económico de la Universidad Rafael Landívar, reciben financiamiento de Open Society Foundations y la organización neerlandesa HIVOS. También recibe un financiamiento de la Fundación alemana Friedrich Ebert Stiftung, y la agencia de noticias EFE les permite publicar contenidos.

Tucumán Zeta fue creada en 2012 por Pedro Noli, Exequiel Svetliza y Bruno Cirnigliaro; se considera la primera revista digital de Tucumán, y en general del norte de Argentina:

Mediante la crónica periodística contamos historias que ocurren acá, en nuestra provincia. Con lujo de detalle, las narramos para nosotros, los tucumanos. Aunque si usted no es de acá, venga, adelante, es muy bienvenido, pase y conozca este universo maravilloso que es mucho más amplio que la empanada más rica del país. (Noli 2012: web de Tucumán Zeta)

Confidencial es una revista nicaragüense, liderada por Carlos Fernando Chamorro. Fue creada en 1996 y ha apostado por el periodismo en profundidad, publica reportajes y crónicas sobre violencia, seguridad, migración, corrupción y desigualdad.

Cosecha Roja, la Red Latinoamericana de Periodismo Judicial, es otro proyecto liderado por Cristian Alarcón y editado por el periodista argentino Sebastián Hacher. La revista digital publica temas que analizan la génesis, el desarrollo y las posibles salidas de los temas de violencia en América Latina.

Frontera D nació en 2009, es una iniciativa española, creada por el periodista Alfonso Armada. Es una revista digital que se ocupa del periodismo narrativo, la crónica y el ensayo. Llama la atención que un medio español hable de crónica, ya que en España no se entiende la crónica como en América Latina, sino que se le relaciona más con las columnas de opinión.

Radio Ambulante es un proyecto que nació en los Estados Unidos y es liderado por el cronista y escritor peruano Daniel Alarcón; está inspirado en el famoso programa This American Life y presenta historias en español para ser escuchadas a través de la red. El objetivo es llevar la crónica a la radio, aunque también dar cabida a historias de ficción. En el año 2014 ganó el premio García Márquez de periodismo: 
El día a día de R.A. (Radio Ambulante) es amplio, cosmopolita. Escucho hoy un audio de Venezuela; mañana, de Cuba; pasado, de Argentina, de México o de Chile. El trabajo mismo obliga a ver las cosas desde la perspectiva de alguien ajeno, de escuchar su voz como si estuviera susurrándome a la oreja. Y eso, día tras día, mes tras mes, me ha dado una noción casi Bolivariana (sin caer en ideologías baratas, por supuesto) de nuestra región, de nuestros países, tan únicos, tan complejos, tan trágicos, pero a la vez tan llenos de vida. (Alarcón 2014: web Radio Ambulante)

La revista Sole nació en Colombia gracias a la iniciativa del antropólogo y periodista Rafael Mayo; es un medio digital que se concentra en la investigación y el periodismo narrativo, que intenta dar cabida a personajes cotidianos, alejados de los reflectores y de las cámaras, ajenos a las primeras páginas de los periódicos.

Así como estas, hay muchas otras revistas que han ayudado a la consolidación de la crónica en América Latina, que le han dado un soporte a un género complejo y costoso, que han creído y le han apostado a una serie de cronistas, como lo hicieron las revistas en Estados Unidos durante la época del llamado Nuevo Periodismo. Sin las revistas no podría explicarse la creciente notoriedad que ha tenido la crónica latinoamericana actual.

\section{CONCLUSIONES}

1. Al igual que en el Nuevo Periodismo norteamericano, en el desarrollo de la crónica latinoamericana actual han jugado un papel fundamental una serie de revistas que han permitido contar historias de largo aliento; le han brindado tiempo, recursos y espacio a una serie de autores consagrados y a jóvenes promesas que han logrado un reconocimiento al publicar su trabajo.

2. Otra similitud con el Nuevo Periodismo es el momento coyuntural en el que surge. En el caso latinoamericano, este auge de la crónica coincide con problemáticas como la migración, la violencia, el narcotráfico, lo monstruoso, lo extravagante, el sexo, el desarrollo de la cocina, el crecimiento de los viajeros latinoamericanos hacia diferentes países en función de turismo; esas situaciones necesitaban otra manera de contarse y por eso surgió una serie de cronistas que 
han tomado el pulso a la realidad y se han apoyado en una serie de revistas para relatarlo.

3. También hay una similitud en la notoriedad que han tenido ciertos autores latinoamericanos, que llenan auditorios, ofrecen charlas en distintos países, son publicados en otros idiomas. Eso sí, hay diferencias sustanciales, como el dinero que pueden pagar las revistas latinoamericanas y la cantidad de libros que venden. Los Nuevos Periodistas se convirtieron en personas que podían vivir de la escritura, pero en América Latina es mucho más complicado y la mayoría de cronistas realiza otras labores para llevar una vida decente.

4. Algunas revistas han logrado perdurar en el tiempo, otras desaparecen poco después de ser fundadas, algunas resisten los embates de la iliquidez económica. Algunas surgen para reemplazar a las que estaban, pero permanecen varias publicaciones, en diferentes países de América Latina y actúan como el ecosistema favorable para que se sigan publicando buenas historias de no ficción.

5. Internet, aparte de ser un medio de difusión, también se ha convertido en una plataforma para el desarrollo de revistas que han servido para financiar y dar a conocer el trabajo de los cronistas latinoamericanos.

6. Muchas de estas revistas han servido para que algunos cronistas obtengan buena parte de su sustento con la escritura. El nombre de algunos de ellos está íntimamente ligado a ellas; pero ya no es necesario que el nombre de un escritor esté vinculado al de una publicación específica, porque algunos desarrollan sus propios proyectos y crean nuevas revistas que ayudan a nutrir el panorama.

7. Sin el soporte de las revistas sería imposible concebir el auge y el reconocimiento que ha tenido la crónica latinoamericana en los últimos años. En las revistas es donde ha nacido la mayoría de las iniciativas que después se han convertido en libros de autores o en antologías. Además, los textos que han sido finalistas y que han ganado los premios de periodismo más prestigiosos nacieron bajo el amparo de las revistas que se convirtieron en el ecosistema más favorable para su desarrollo. 


\section{BIBLIOGRAFÍA}

Adorno, T. Teoría estética. Madrid: Orbis, 1983.

Alarcón C. Conferencia en la Fundación Tomás Eloy Martínez. Buenos Aires, Argentina, 2013.

Almazán, A. Entrevista. Realizada por el autor del artículo en Medellín, Colombia, en noviembre de 2013.

Avilés, M. Entrevista. Realizada por el autor del artículo en Lima, Perú, en octubre de 2013.

Barrera, C. Historia del periodismo universal. Barcelona: Ariel, 2004.

Bajtín, M. Estética de la creación verbal. Madrid: Siglo XXI Editores, 2011.

Benavides, J. Entrevista. Realizada por el autor del artículo por correo electrónico en marzo de 2014.

"Juan Villoro, el maestro de la dispersión total". Revista Sole. Disponible en: http://www.revistasole.com/2014/10/juan-villoro-el-maestro-de-la.html. Consultado el 20 de octubre de 2014.

Cantú, E. Entrevista. Realizada por el autor del artículo en Lima, Perú, en octubre de 2013.

Carrión, J. Mejor que ficción. Crónicas ejemplares. Barcelona: Anagrama, 2012.

Chillón, A. Literatura y periodismo. Una tradición de relaciones promiscuas. Barcelona, Universitat Autónoma de Barcelona, 1999.

Dada, C. Entrevista. Realizada por el autor del artículo en Medellín, Colombia, en noviembre de 2013.

Ethel, C. "La invención de la realidad". Babelia 868, El País, 12 de julio de 2008. Disponible en: http://elpais.com/diario/2008/07/12/babelia/1215819552_850215.html. Consultado el 26 de julio de 2014.

Garzón, D. Entrevista. Realizada por el autor del artículo en Bogotá, Colombia, en enero de 2013.

Genette, G. Ficción y dicción. Madrid: Lumen, 1991.

Jaramillo, D. Antología de la crónica latinoamericana actual. Madrid: Alfaguara, 2011.

Jiménez, C. Entrevista. Realizada por el autor del artículo en Bogotá, Colombia, en diciembre de 2013.

Jursich, M. Entrevista. Realizada por el autor del artículo en Bogotá, Colombia, en diciembre de 2013.

Lafuente, S. Entrevista. Realizada por el autor del artículo por correo electrónico en mayo de 2014.

León, J. Entrevista. Realizada por el autor del artículo en Guayaquil, Ecuador, en septiembre de 2013.

Martínez, O. Entrevista. Realizada por el autor del artículo en Medellín, Colombia, en noviembre de 2013.

Mochkofsky, G. El Puercoespín en pausa. En: http://www.elpuercoespin.com.ar/2014/04/01/ el-puercoespin-en-pausa/. Recuperado el 2 de mayo de 2014.

Molano, R. Gatopardo. En: https://gatopardo.com. Recuperado el 15 de marzo de 2014. 
Muñoz, B. Entrevista. Realizada por el autor del artículo en Medellín, Colombia, en noviembre de 2013.

Noli, P. ¿Qué es Tucumán Z? En: https://tucumanzeta.com/que-es-tucuman-zeta/. Recuperado el 4 de marzo de 2014.

Osorno, D. Adiós a Gatopardo. Disponible en http://www.gatopardo.com/detalleBlog. php?id=380. Recuperado el 2 de mayo de 2014.

Palet, A. Entrevista. Realizada por el autor del artículo en Bogotá, Colombia, en diciembre de 2013.

Pinheiro, D. Entrevista. Realizada por el autor del artículo en Medellín, Colombia, en noviembre de 2013.

Puerta, A. "El periodismo narrativo o una manera de dejar huella de una sociedad en una época”. Anagrama. Volumen 9, número 18. Universidad de Medellín. Medellín, 2011.

“Crónica latinoamericana. ¿Existe un boom de la no ficción”. Estudios sobre el mensaje periodístico. Volumen 23. Número 1, 2017.

Restrepo, F. Primer editorial como editor de Gatopardo. Disponible en http://www.gatopardo. com/detalleBlog.php?id=386. Recuperado el 6 de julio de 2014 .

Vallejo, M. Entrevista. Realizada por el autor del artículo en Bogotá, Colombia, en diciembre de 2013.

Vera, C. Entrevista. Realizada por el autor del artículo en Quito, Ecuador, en octubre de 2013.

Villanueva Chang, J. Entrevista. Realizada por el autor del artículo en Buenos Aires, Argentina, en mayo de 2013

Weingarten, M. La banda que escribía torcido. Madrid: Libros del KO, 2013. 